University of Nebraska - Lincoln

DigitalCommons@University of Nebraska - Lincoln

Papers in the Earth and Atmospheric Sciences

Earth and Atmospheric Sciences, Department

2005

\title{
High-Resolution Ocean Color Remote Sensing of Benthic Habitats: A Case Study at the Roatan Island, Honduras
}

\author{
Deepak R. Mishra \\ University of Nebraska-Lincoln, dmishra@calmit.unl.edu \\ Sunil G. Narumalani \\ University of Nebraska-Lincoln, snarumalani1@unl.edu \\ Donald Rundquist \\ University of Nebraska-Lincoln, drundquist1@unl.edu \\ Merlin P. Lawson \\ University of Nebraska-Lincoln, mlawson1@unl.edu
}

Follow this and additional works at: https://digitalcommons.unl.edu/geosciencefacpub

Part of the Earth Sciences Commons

Mishra, Deepak R.; Narumalani, Sunil G.; Rundquist, Donald; and Lawson, Merlin P., "High-Resolution Ocean Color Remote Sensing of Benthic Habitats: A Case Study at the Roatan Island, Honduras" (2005). Papers in the Earth and Atmospheric Sciences. 129.

https://digitalcommons.unl.edu/geosciencefacpub/129

This Article is brought to you for free and open access by the Earth and Atmospheric Sciences, Department of at DigitalCommons@University of Nebraska - Lincoln. It has been accepted for inclusion in Papers in the Earth and Atmospheric Sciences by an authorized administrator of DigitalCommons@University of Nebraska - Lincoln. 


\title{
High-Resolution Ocean Color Remote Sensing of Benthic Habitats: A Case Study at the Roatan Island, Honduras
}

\author{
Deepak R. Mishra, Sunil Narumalani, Donald Rundquist, and Merlin Lawson
}

\begin{abstract}
Natural resource managers clamor for detailed reef habitat maps for monitoring smaller scale disturbances in reef communities. Coastal ocean color remote sensing techniques permit benthic habitats to be explored with higher resolution than ever before. The objective of this research was to develop an accurate benthic habitat map for an area off the northwest coast of Roatan Island, Honduras, using high-resolution multispectral IKONOS data. Atmospheric (Rayleigh and aerosol path radiance) and water column corrections (water depth and water column attenuation) were applied to the imagery, making it a robust method for mapping benthic habitats. Water depth for each pixel was calculated based on a site-specific polynomial model. A mechanistic radiative transfer approach was developed that removed the confound effect of the water column (absorption and scattering) from the imagery to retrieve an estimate of the bottom reflectance (albedo). Albedos were $\leq \mathbf{1 2 \%}$ for seagrass benthos, $12 \%$ to $24 \%$ for coral areas, and $\geq 24 \%$ for sand-dominated areas. The retrieved bottom albedos were then used to classify the benthos, generating a detailed map of benthic habitats, followed by accuracy assessment.
\end{abstract}

Index Terms-Accuracy assessment, atmospheric correction, bathymetry, benthic habitats, bottom albedo, IKONOS, radiative transfer, water column correction.

\section{INTRODUCTION}

$\mathbf{S}_{\mathrm{b}}$ ATELLITE remote sensing techniques have been employed by many researchers to map general benthic habitat types (e.g., sand, seagrass, coral reefs, hard substrate) in coral reef environments. Those evaluating the utility of the Thematic Mapper (TM) have mapped subtidal coastal habitats [1], delineated sand bottoms [2], digitally classified coral reef zones [3], evaluated the benthos [4], and performed time series analyses [5]. Similarly, researchers have used Systeme Pour l'Observation de la Terre (SPOT) (20 m) imagery to survey coral reef abundance [6] and apply a spatial statistical approach to multidate SPOT data to identify coral stress [7]. Dobson and Dustan [5] noted that

\footnotetext{
Manuscript received December 9, 2004; revised January 9, 2005. This work was supported in part by the Center for Advanced Land Management Information Technologies, in part by the University of Nebraska Research Council, in part by the School of Natural Resources, in part by the Department of Geosciences, and in part by the Office of the Vice Chancellor for Research and Graduate Studies, University of Nebraska-Lincoln.

D. R. Mishra, S. Narumalani, and D. Rundquist are with the Center for Advanced Land Management Information Technologies, School of Natural Resources, University of Nebraska, Lincoln, NE 68588-0517 USA (e-mail: dmishra@calmit.unl.edu).

M. Lawson is with the Department of Geosciences, University of Nebraska, Lincoln, NE 68588-0340 USA.

Digital Object Identifier 10.1109/TGRS.2005.847790
}

coral reefs consist of a mosaic of fine-scale features between $1-5 \mathrm{~m}$ in size with complex optical signatures that blend as individual fields of view become larger. Thus, the relatively coarse spatial resolutions of TM and SPOT have limited the effectiveness of spaceborne platforms for coral reef studies. Mumby et al. [8] noted that although TM and SPOT can detect benthic signals through clear water to a depth of approximately $25 \mathrm{~m}$, the coarse spatial and spectral resolutions of these systems limit classification results to broad-based geomorphological information, rather than biotic assemblages. The same authors concluded that a pixel size of 3-4 m is probably optimal for surveying tropical marine environments. Satellites such as IKONOS and QuickBird offer exactly such spatial resolutions and would be deemed appropriate for evaluating coral habitats.

However, the most difficult aspect of benthic mapping using satellite imagery is the tendency of variations arising from changes in water depth, bottom type, and scattering and absorption in the water column (by chlorophyll, suspended sediments, colored dissolved organic matter, etc.) to be indistinguishable. Substrate reflectance and water column properties (depth, absorption and scattering coefficient) are intimately associated and conventional analytical methods are unable to resolve one measure accurately unless the other is already known for each pixel. For example, if the water column diffuse attenuation coefficient [9] is known for each spectral band and the depth for each pixel has been measured independently, the at-surface reflectance of the substrate can be predicted, thus permitting spectral classification and benthic mapping [10], [11]. Incorporation of important parameters such as water depth, absorption and scattering coefficients will allow us to estimate the bottom albedo accurately, which can improve habitat mapping [12].

The approach presented here solves the confounding influence of depth and water column attenuation on substrate reflectance. We derived water depths using multiband ratio method [13], [14] and water optical properties [15]-[17] from high-resolution IKONOS data. These parameters were subsequently used in various bio-optical algorithms [15]-[19] to deduce bottom albedo and ultimately to prepare an accurate benthic habitat map. The approach described in the paper provides useful steps toward using high spatial resolution data for coastal resource assessment.

\section{STUDY AREA}

Roatan Island lies between $16^{\circ} 15^{\prime}$ to $16^{\circ} 25^{\prime} \mathrm{N}$ and $86^{\circ} 22^{\prime}$ to $86^{\circ} 37^{\prime} \mathrm{W}$. It is the largest of the Bay Islands of Honduras, and 


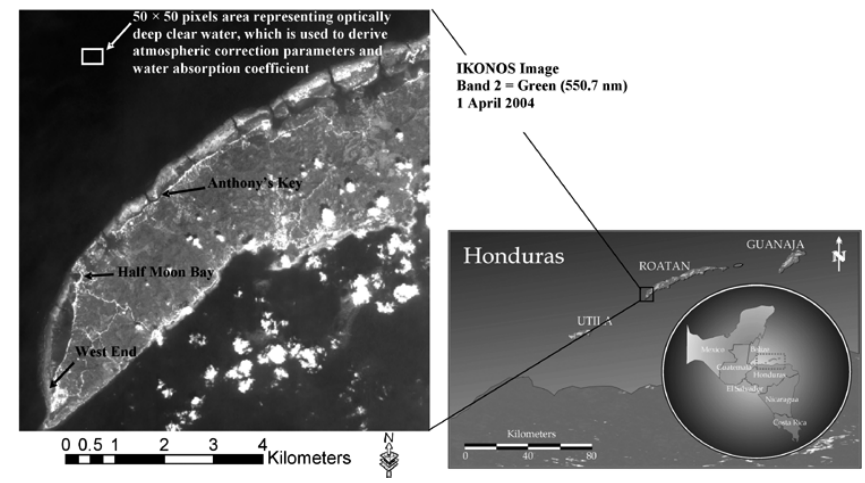

Fig. 1. (Right) Location of Roatan Island, Honduras, in Central America (circle inset) and (left) an image-map of the IKONOS scene acquired on 1 April 2001.

is located in the western portion of the Caribbean Sea approximately $50 \mathrm{~km}$ north of the mainland. The focus of our research was the Sandy Bay Marine Reserve and the north shore of the westernmost portion of the island (Fig. 1). Roatan's climate is typical of the hot and humid tropical environments, with an average annual precipitation of $215 \mathrm{~cm} /$ year. Mean monthly temperatures range from $25.4^{\circ} \mathrm{C}$ in January to $28.9^{\circ} \mathrm{C}$ in September [20]. Over the past century, damaging hurricanes have occurred at a rate of one per decade, with the most serious being Hurricanes "Fifi" (1974) and "Mitch" (1998).

The reefs of the Bay Islands contain at least 52 species of stony corals, at depths ranging from 2-15 m. Coral species include Star corals (Montastrea annularis, $M$. franksi, M. faveolata, M. cavernosa), Brain corals (Colpophylia natans, Diploria spp.), Sheet and Lettuce corals (Agaricia agaricites, A. larcki, A. undata, A. fragilis, and Leptosiris cuculatta), Flower coral (Eusmillia fastigiata), Pillar coral (Dendrogyra cylindrus), Boulder Brain coral (Colpophylia natans), Symmetrical Brain coral (Diploria strigosa), and Massive Starlet coral (Siderastrea siderea). The bays contain highly productive seagrass beds, with Turtle Grass (Thalassia testudinum) being the most abundant species at Roatan. The seagrasses provide habitat for anemones, mollusks, crabs, shrimp, and many other organisms. This summary of Roatan's habitats was taken from Keck [21].

\section{Methods AND MATERIALS}

\section{A. In Situ Data}

Two independent in situ datasets were collected: one for model calibration and one for model validation. The model calibration datasets were obtained from a vertically stable buoy guided by a diver along a series of transects. This buoy served as a platform for a Trimble TDC1 Asset Surveyor GPS antenna, a Sony Hi-8 mm TRV-320 digital video camera encased in a T-9 housing (Undersea Video Housings), and a Lowrance depth transducer (Fig. 2). The data were collected simultaneously $1 \mathrm{~m}$ below the air/water interface; consequently, the instantaneous field of view (IFOV) of the images and hyperspectral readings varied as a function of depth and ranged from 0-35 m. However, recorded images and the GPS-synchronous timestamp were of suitable quality to determine the primary benthic cover at sample locations, and the IFOV was calculated based on depth measured by the Lowrance sonar.

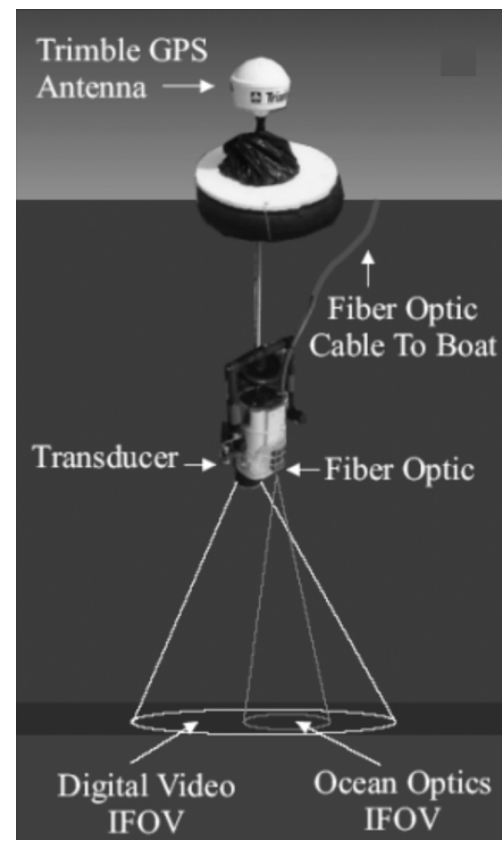

Fig. 2. Components of a vertically stable GPS buoy used in in situ data collection for bathymetry model calibration.

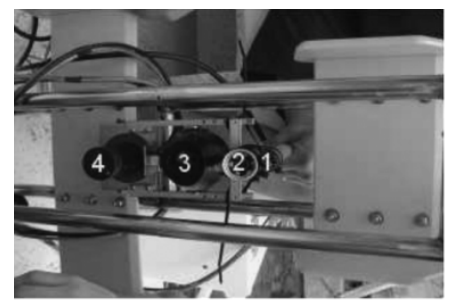

(a)

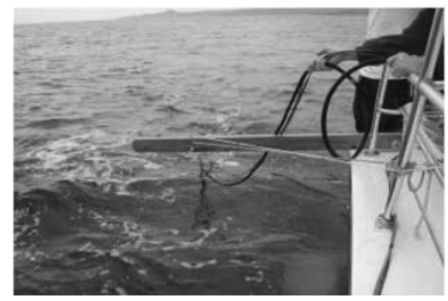

(c)

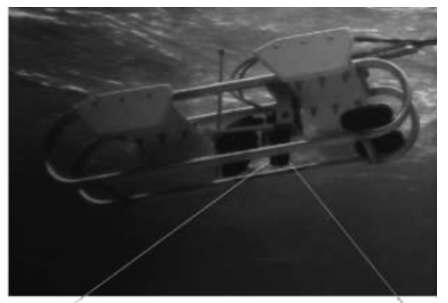

(b)

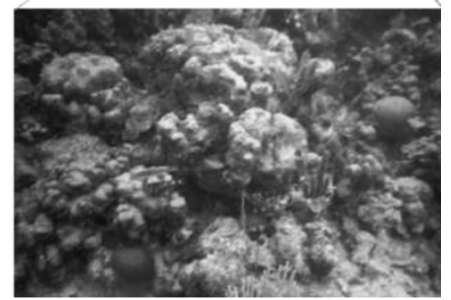

(d)
Fig. 3. (a) Components of towfish, a multisensor platform designed by CALMIT includes 1) ocean optics hyperspectral sensor, 2) camera one 3) camera two, 4) transducer. (b) View of towfish from under water. (c) Towfish in action. (d) Typical coral bottom types photograph taken by towfish camera.

A towed sensor platform (the "towfish") built by Shark Marine (St. Catharines, ON, Canada) was used to acquire model validation datasets [Fig. 3(a) and (b)]. The towfish was constructed to resist wave action, so it moved through the water at a relatively constant, horizontal position while being towed at a speed of approximately $3 \mathrm{~km} / \mathrm{h}$ [Fig. 3(c)]. Depths were logged continuously along the selected transects. A high-resolution "minicamera" imaged the bottom at the locations where depths were logged [Fig. 3(d)]. A differential GPS was placed on the boat and the offset to the towfish was calculated. Mathematically, the exact location of the transducer was determined by correcting for the distance between the GPS unit and the transducer $(6.2 \mathrm{~m})$, the angle at which the boat was 
moving (variable), and the position of the transducer relative to the surface of the water $(0.3048 \mathrm{~m}$ below). Data for separate locations were collected for each of three bottom types: coral, seagrass, and sand.

\section{B. Satellite Data}

IKONOS panchromatic and multispectral images were collected for the Roatan study site on April 1, 2001 (Fig. 1). Primary radiometric corrections by Space Imaging, Inc., Thornton, $\mathrm{CO}$, were designed to remove any spatial variations in digital output or artifacts that may occur in the image data. In addition, Space Imaging had performed geometric corrections ( \pm 1 pixel; nearest neighbor) on the image to remove any optical or positional distortions. The brightness values (BVs) for each band were converted to top of the atmosphere (TOA) radiance by applying calibration coefficients referenced to well-characterized spectroradiometric targets. ${ }^{1}$

\section{Land and Cloud Masking}

When extracting aquatic information, it is useful to eliminate all upland and terrestrial features [22]; thus all upland features, as well as boats, piers, and clouds, were masked out of the image. The "land-mask" restricts the spectral range of radiance values to aquatic features and allows for detailed feature discrimination. Radiance values of the near-infrared (NIR) band were used to prepare the binary mask which was subsequently applied to all the IKONOS channels.

\section{First-Order Atmospheric Correction}

In the case of oceanic remote sensing, the total signal received at the satellite altitude is dominated by radiance contributed through atmospheric scattering processes and only $8 \%$ to $10 \%$ of the signal corresponds to the oceanic reflectance [23]. Therefore, it is advisable to correct for atmospheric effects to retrieve any quantitative information for surface waters from the image. The radiance received by a sensor at the top of the atmosphere (TOA) in a spectral band centered at a wavelength $\lambda_{i}, L_{t}\left(\lambda_{i}\right)$, can be divided into the following components [24]:

$$
L_{t}\left(\lambda_{i}\right)=L_{r}\left(\lambda_{i}\right)+L_{a}\left(\lambda_{i}\right)+T\left(\lambda_{i}\right) L_{g}\left(\lambda_{i}\right)+t\left(\lambda_{i}\right) L_{w}\left(\lambda_{i}\right)
$$

where

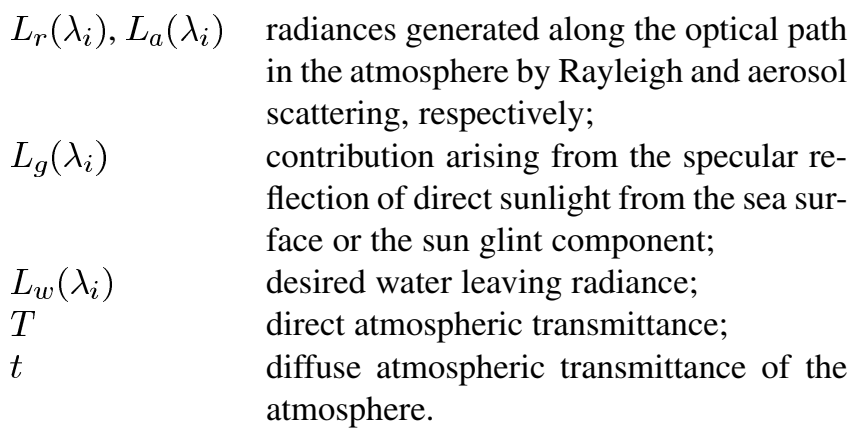

$L_{w}\left(\lambda_{i}\right)$
$T$
$t$

\footnotetext{
${ }^{1}$ See "IKONOS Relative Spectral Response and Radiometric Cal Coefficients," Space Imaging Corp. http://www.spaceimaging.com/products/ikonos/ spectral.htm
}

Note that for a high-visibility environmental condition (in our case visibility $>40 \mathrm{~km}$ ), we ignore any Rayleigh-aerosol multiple scattering and use a quasi-single-scattering approximation. According to Gordon and Voss [25], for areas around the sun glint pattern, $T\left(\lambda_{i}\right) L_{g}\left(\lambda_{i}\right)$ is so large that the imagery is virtually useless and must be discarded. The IKONOS image had negligible sun glint effects, and hence $T\left(\lambda_{i}\right) L_{g}\left(\lambda_{i}\right)$ may be ignored, leaving the largest and most difficult terms to estimate-i.e., the path radiances due to Rayleigh and aerosol scattering. Consequently, (1) can be written as

$$
L_{t}\left(\lambda_{i}\right)=L_{r}\left(\lambda_{i}\right)+L_{a}\left(\lambda_{i}\right)+t\left(\lambda_{i}\right) L_{w}\left(\lambda_{i}\right) .
$$

1) Computation of Rayleigh Path Radiance $L_{r}\left(\lambda_{i}\right)$ : Rayleigh atmospheric scattering primarily affects the direction of short wave radiation, resulting in haze that affects primarily the blue and green bands. For Landsat MSS data, the Rayleigh scattering is four times as great in the green band of the electromagnetic spectrum than it is in the NIR band [26]. Rayleigh path radiance can be computed using Gordon and Clark [27]

$$
L_{r}\left(\lambda_{i}\right)=\frac{F_{0}^{\prime}(\lambda) \omega_{0} \tau_{r} P_{r}}{4 \pi \cos \theta_{0}}
$$

where

$F_{0}^{\prime}(\lambda)$ instantaneous extraterrestrial solar irradiance, $F_{0}(\lambda)$, which is reduced by two trips through the ozone layer and is computed by

$$
F_{0}^{\prime}(\lambda)=F_{0}(\lambda) e^{-\tau_{O z}\left(1 / \cos \theta_{v}+1 / \cos \theta_{0}\right)}
$$

$F_{0}(\lambda)$ values are taken from Nickel and Labs [28];

$\omega_{0} \quad$ single scattering albedo equal to 1 ;

$\tau_{r} \quad$ Rayleigh optical thickness;

$\tau_{O z} \quad$ ozone optical thickness;

$P_{r} \quad$ Rayleigh scattering phase function;

$\theta_{v} \quad$ satellite viewing zenith angle;

$\theta_{0} \quad$ solar zenith angle.

The value of Rayleigh optical thickness $\left(\tau_{r}\right)$ at any atmospheric pressure $P$ is given by Hansen and Travis [29]

$$
\tau_{r}=\frac{P}{P_{0}}\left[0.008569 \lambda^{-4}\left(1+0.0113 \lambda^{-2}+0.00013 \lambda^{-4}\right)\right.
$$

where

$\lambda \quad$ wavelength in microns;

$P_{0} \quad$ standard atmospheric pressure of $1013.25 \mathrm{mb}$.

The Rayleigh scattering phase function is given by Doerffer [30]

$$
P_{r}\left(\theta_{ \pm}\right)=\frac{3}{4}\left(1+\cos ^{2} \theta_{ \pm}\right)
$$

where

$\theta_{ \pm} \quad$ forward/backward scattering angle and it is related to the sensor viewing and solar illumination directions through

$$
\cos \theta_{ \pm}= \pm \cos \theta_{0} \cos \theta_{v}-\sin \theta_{0} \sin \theta_{v} \cos \left(\phi_{v}-\phi_{0}\right)
$$


where

$\theta_{0}$ solar zenith angle;

$\phi_{0}$ solar azimuth angle;

$\theta_{v}$ satellite viewing zenith angle;

$\phi_{v}$ satellite viewing azimuth angle.

2) Computation of Aerosol Path Radiance $L_{a}\left(\lambda_{i}\right)$ : To compute aerosol scattering for the scene, we assumed that for the NIR band $4(805 \mathrm{~nm})$ the water leaving radiance $L_{w}\left(\lambda_{i}\right)$ over the clear-water pixels would be close to zero because of the absorption by water. Hence, the measured TOA radiance $L_{t}\left(\lambda_{i}\right)$ in the NIR is the sum of Rayleigh $L_{r}\left(\lambda_{i}\right)$ and aerosol path radiance $L_{a}\left(\lambda_{i}\right)$. By subtracting Rayleigh path radiance from the TOA radiance in clear water pixels (Fig. 1) of the NIR band, one can deduce aerosol path radiance for those pixels. We computed the contribution of aerosol scattering for these pixels as

$$
L_{a}^{0}\left(\lambda_{4}\right)=L_{t}^{0}\left(\lambda_{4}\right)-L_{r}^{0}\left(\lambda_{4}\right)
$$

where

$$
\begin{array}{ll}
L_{a}^{0}\left(\lambda_{4}\right) & \begin{array}{l}
\text { contribution of aerosol scattering over the clear } \\
\text { water pixels at band } 4 ;
\end{array} \\
L_{t}^{0}\left(\lambda_{4}\right) & \begin{array}{l}
\text { total radiance observed over the clear water pixel } \\
\text { at band } 4 ;
\end{array} \\
L_{r}^{0}\left(\lambda_{4}\right) & \begin{array}{l}
\text { contribution of Rayleigh scattering over the clear } \\
\text { water pixels at band } 4 .
\end{array}
\end{array}
$$

Aerosol path radiance at any wavelength, $L_{a}\left(\lambda_{i}\right)$, can be calculated from $L_{a}^{0}\left(\lambda_{4}\right)$ and is given as

$$
L_{a}\left(\lambda_{i}\right)=S\left(\lambda_{i}, \lambda_{4}\right) L_{a}^{0}\left(\lambda_{4}\right)
$$

where

$S$ ratio, which is related to the optical properties of the aerosol through

$$
S\left(\lambda_{i}, \lambda_{4}\right)=\varepsilon\left(\lambda_{i}, \lambda_{4}\right) \frac{F_{0}^{\prime}\left(\lambda_{i}\right)}{F_{0}^{\prime}\left(\lambda_{4}\right)} .
$$

Gordon and Wang [31] proposed an exponential relationship for the spectral behavior of aerosol optical depth which has been used for the SeaWiFS atmospheric correction algorithm. The algorithm uses an Angstrom exponent $(\varepsilon)$ based on an exponential relation using spectral data at 765 and $865 \mathrm{~nm}$ for each pixel. The aerosol optical thickness is extrapolated to the visible channels using this relationship. Because the IKONOS sensor does not have two bands in the NIR to calculate the Angstrom exponent, $\varepsilon\left(\lambda_{i}, \lambda_{4}\right)$ was set to unity (i.e., aerosol reflectance/absorption are constant through out the scene), which is characteristic of maritime aerosols at high relative humidities [25]. We also assumed that the aerosols are homogenously distributed over the entire area of interest, so that $L_{a}^{0}\left(\lambda_{4}\right)$, computed over the clear water (Fig. 1), is assumed to be constant over the entire IKONOS scene. Hence, the aerosol path radiance for the three visible bands was computed using (9).

3) Computation of Diffuse Transmittance $t\left(\lambda_{i}\right)$ : Diffuse transmittance $t\left(\lambda_{i}\right)$ is defined as the water leaving radiance in

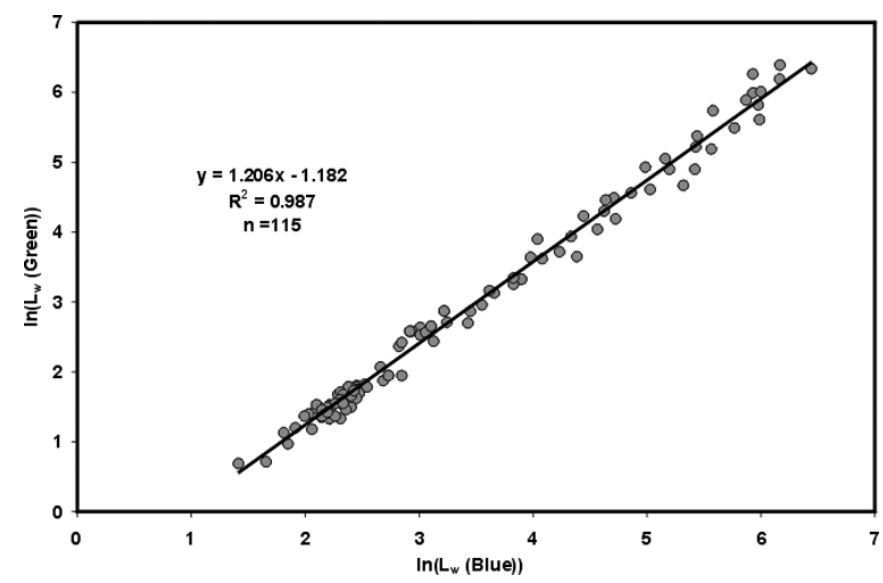

Fig. 4. Model calibration dataset taken from GPS buoy showing the regression between log-transformed water-leaving blue versus green radiance values for several bottom types.

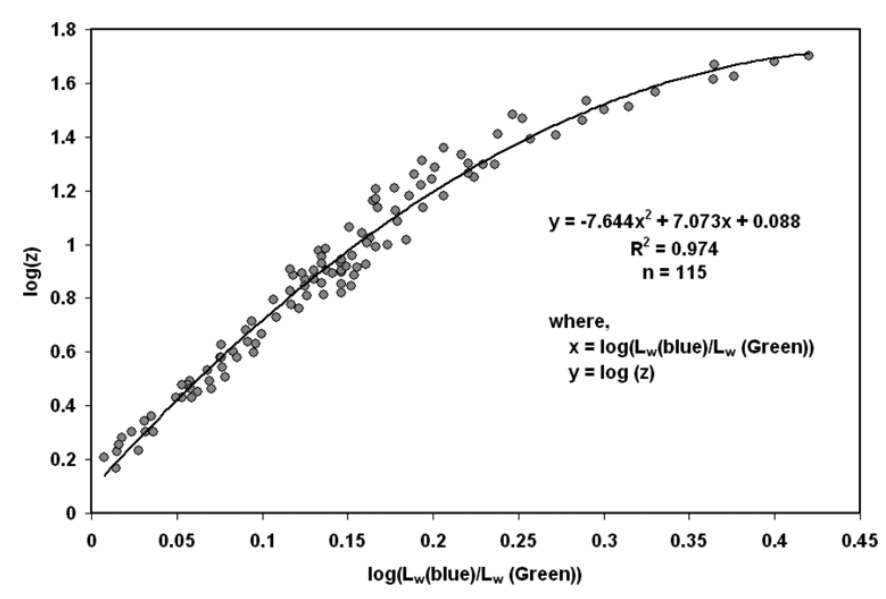

Fig. 5. Relationship between bottom depth and ratio of blue to green water leaving radiance (14). The polynomial equation shown in the graph was used to derive bathymetry map for the study site.

a particular viewing direction $\left(\theta_{0}, \theta_{v}\right)$ transmitted to the top of the atmosphere and is given by

$$
t\left(\lambda_{i}\right)=\exp \left[-\left(\frac{\tau_{r}(\lambda)}{2}+\tau_{O z}(\lambda)\right)\left(\frac{1}{\cos \theta_{0}}+\frac{1}{\cos \theta_{v}}\right)\right]
$$

where

$\tau_{r}(\lambda) \quad$ Rayleigh optical thickness;

$\tau_{O z}(\lambda) \quad$ ozone optical depth, and ozone optical depth for a concentration of DU (Dobson units or milliatmosphere centimeters) is given by

$$
\tau_{O z}(\lambda)=k_{O z}(\lambda) \frac{D U}{1000}
$$

where

$k_{O z}(\lambda) \quad$ ozone absorption coefficient taken from Leckner [32].

The desirable water-leaving radiance $L_{w}\left(\lambda_{i}\right)$ at a specific wavelength was computed by rewriting (2) as

$$
L_{w}\left(\lambda_{i}\right)=\frac{L_{t}\left(\lambda_{i}\right)-L_{r}\left(\lambda_{i}\right)-L_{a}\left(\lambda_{i}\right)}{t\left(\lambda_{i}\right)} .
$$


TABLE I

ABSORPTION AND BACKSCATtERING COEFFICIENTS DERIVED From the $50 \times 50$ ClEAR WATER PiXEL Window (SHOWN IN Fig. 1) OF THE IKONOS IMAGE

\begin{tabular}{ccccc}
\hline Wavelength $(\lambda)(\mathrm{nm})$ & $\begin{array}{c}\text { Pure Water } \\
\text { Absorption } \\
\text { Coefficient }\left(\mathrm{a}_{\mathrm{w}}\right)\left(\mathrm{m}^{-1}\right)\end{array}$ & $\begin{array}{c}\text { Total Absorption } \\
\text { Coefficients }(\mathrm{a}(\lambda))\left(\mathrm{m}^{-1}\right)\end{array}$ & $\begin{array}{c}\text { Pure Water } \\
\text { Backscattering } \\
\text { Coefficients }\left(\mathrm{b}_{\mathrm{bw}}\right)\left(\mathrm{m}^{-1}\right)\end{array}$ & $\begin{array}{c}\text { Total backscattering } \\
\text { Coefficients }(\mathrm{bb}(\lambda))\left(\mathrm{m}^{-1}\right)\end{array}$ \\
\hline 480.3 & 0.0127 & 0.0216 & 0.0017 & 0.0049 \\
550.7 & 0.0565 & 0.0617 & 0.00095 & 0.0039 \\
664.8 & 0.4245 & 0.4310 & 0.0004 & 0.0031 \\
\hline
\end{tabular}

\section{E. Shallow Marine Bathymetry Estimation}

The ultimate goal of this research was to derive the bottom albedo and carry out benthic mapping of shallow marine habitats around Roatan Island, Honduras. To derive bottom albedo, water depth should be known for the study area. The depths will be used to eliminate the change in reflectance that is attributable to variable depth, and water column attenuation effects. Researchers have been attempting to estimate depth of shallow water using remote sensing for several years (e.g., [14]). A common problem among most studies is that the seafloor is covered by a patchwork of organisms and substrates that have different albedos, ranging from very dark (e.g., coral $\sim 0.12$ ) to very bright (e.g., sand $\sim 0.3$ ). The difficulty is that a dark object strongly absorbs light and will appear to be deeper than it really is. This effect is not as severe for bright objects, which absorb less strongly. Thus, for coral and sand at the same true depth, the coral virtually always appears to be deeper than the sand. Previous researchers have mapped water depth by assuming that a pair of wavebands can be identified such that the ratio of the radiances in these two bands was the same for all the bottom types within a given scene [14], [33]. Following this assumption, we developed a site-specific algorithm to map high-resolution bathymetry using radiance measured with the IKONOS sensor. Essentially, we identified a ratio of wavebands (blue and green) that is constant for all bottom types (Fig. 4). With these bands having different water absorptions, one band will have arithmetically lesser values than the other. As the depth increased, radiance of the band with higher absorption (green) decreased proportionally faster than the band with lower absorption (blue) and the radiance ratio of the blue to the green increased. This method also compensate implicitly for variable bottom types. A change in bottom albedo affects both bands similarly, but changes in depth affect the high-absorption band more [34]. Accordingly, the change in ratio because of depth is much greater than that caused by change in bottom albedo, suggesting that different bottom albedos at a constant depth will still have the same ratio. The log transformed radiance ratio of the two bands (blue, green) was plotted against known depth data $(z)$ to develop a second-order polynomial (Fig. 5)

$$
y=-7.6439 x^{2}+7.0734 x+0.0876
$$

where

$$
\begin{aligned}
y & =\log (z) \\
x & =\log \left[\frac{L_{w}(\text { blue } ; 480.3 \mathrm{~nm})}{L_{w}(\text { green } ; 550.7 \mathrm{~nm})}\right] .
\end{aligned}
$$

The above polynomial equation explained $>97 \%$ of variation $(p<0.001)$ in water depth calibration dataset collected over five transects of various bottom types (coral, sand, seagrass, Mixed: sand/coral/seagrass/algae). Approximately $50 \%$ of the predictions were within $\pm 0.033 \mathrm{~m}$ and the mean residual was $\pm 0.13 \mathrm{~m}$. Equation (14) was used to derive a map of bathymetry across the study site.

\section{F. Deriving Bottom Albedo}

Knowledge of optical bottom albedo for shallow ocean waters is necessary to model the underwater and above-water light field, to enhance underwater object detection or imaging, and ultimately to determine the distribution of benthic habitats [35]. The signals measured by a sensor from above the water surface of a shallow marine environment are highly coupled with phytoplankton abundance (chlorophyll absorption), water column interactions (absorption by water and scattering by suspended sediments), and radiance reflected from the bottom. For the bottom contribution to be retrieved by a sensor the water-column contributions have to be removed and the optical properties of the water-column have to be known or at least be derivable. Lee et al. [15], [16] proposed models to derive water optical properties (e.g., absorption coefficients) from remotely sensed data. Using AVIRIS imagery and spacecraft spectrometers with high spatial and spectral resolution, they successfully separated various shallow water constituents based on their unique spectral contributions. The work described in this section of the paper demonstrates analytically how to derive bottom albedo using IKONOS data, after the removal of atmospheric interferences. Given the limited number of visible bands on the IKONOS sensor, the model has been necessarily simplified.

Remote sensing reflectance $\left(R_{r s}\right)$ is defined as a ratio of the water-leaving radiance $\left(L_{w}\right)$ to downwelling irradiance $\left(E_{d}\right)$ just above the surface. $R_{r s}$ is an apparent optical property [36] controlled by the absorption and scattering properties of the constituents in the water and the bottom albedo and can be written as

$$
R_{r s}(\lambda)=R_{r s}^{w}(\lambda)+R_{r s}^{b}(\lambda)
$$

where

$R_{r s}^{w}(\lambda)$ remote sensing reflectance from water column;

$R_{r s}^{b}(\lambda)$ remote sensing reflectance from the bottom.

Lee et al. [15] have further approximated the two terms $R_{r s}^{w}(\lambda)$ and $R_{r s}^{b}(\lambda)$ as follows:

$$
\begin{aligned}
& R_{r s}^{w}(\lambda) \approx 0.05 \frac{b_{b}(\lambda)}{a(\lambda)+b_{b}(\lambda)}\left[1-e^{-3.2\left(a(\lambda)+b_{b}(\lambda)\right) H}\right] \\
& R_{r s}^{b}(\lambda) \approx 0.173 \rho(\lambda) e^{\left[-2.7\left(a(\lambda)+b_{b}(\lambda)\right) H\right]}
\end{aligned}
$$




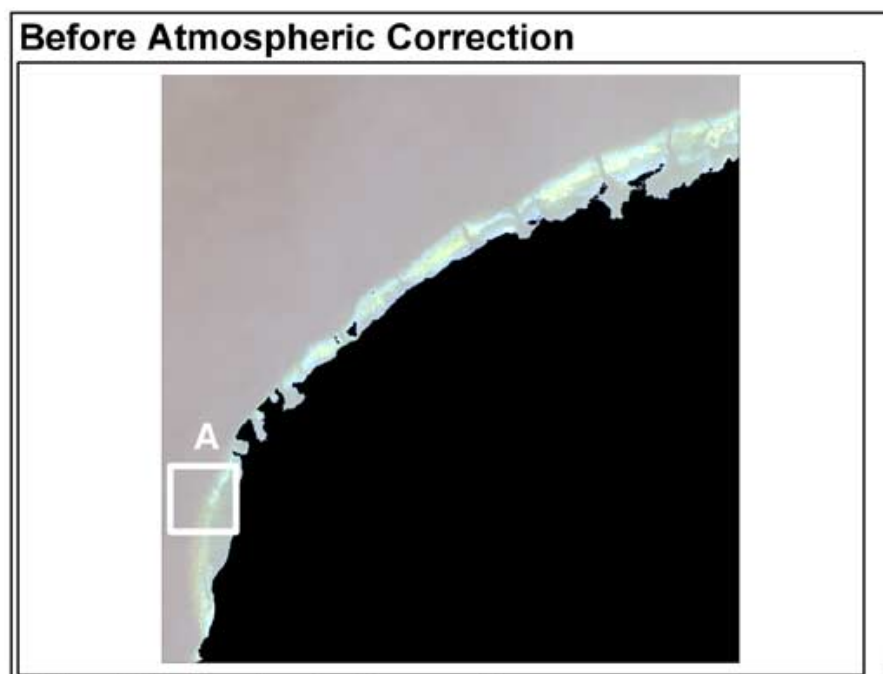

\section{After Atmospheric Correction}

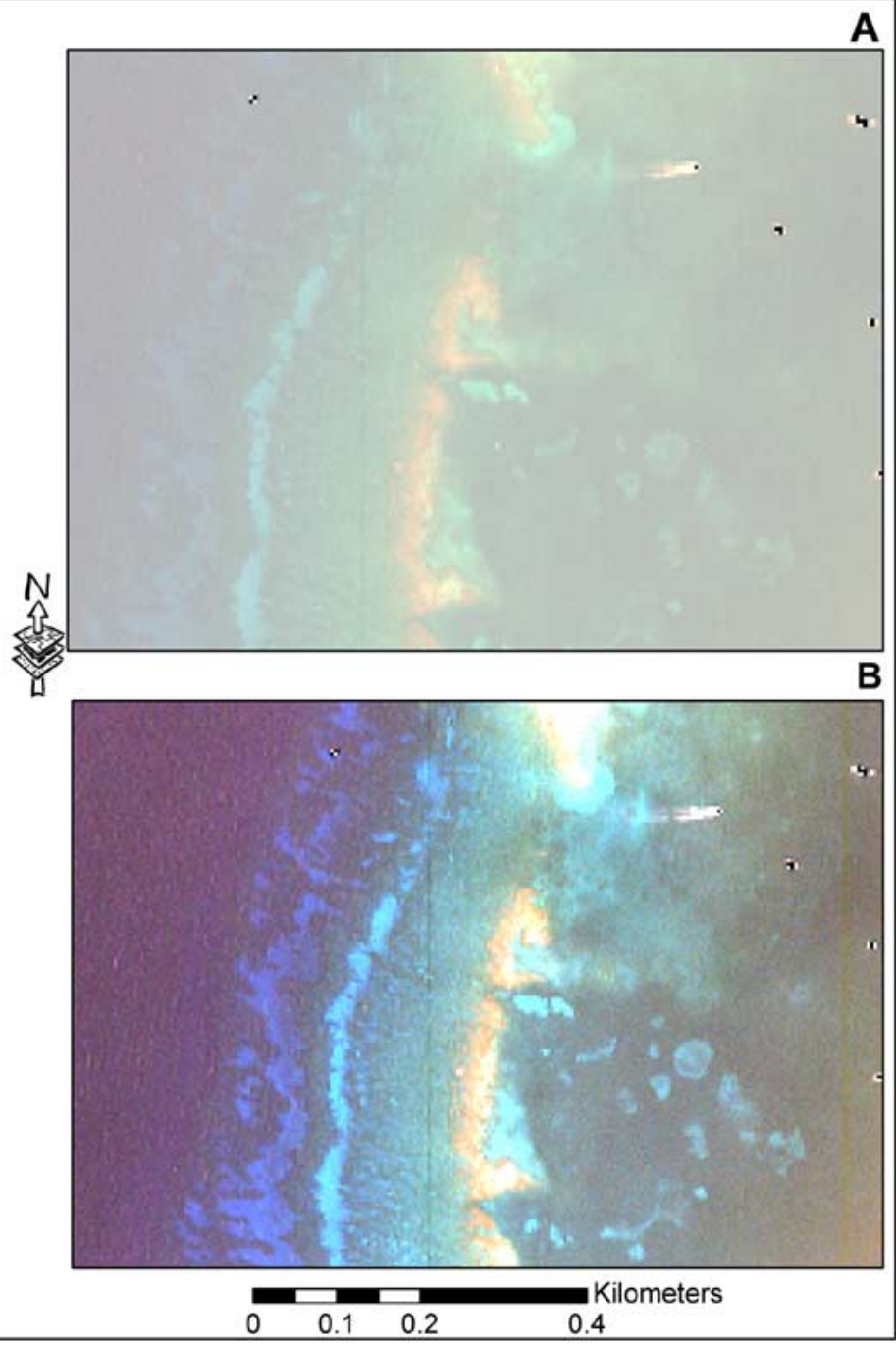

Fig. 6. IKONOS image before and after the atmospheric correction. (A) and (B) are zoomed areas near Sandy Bay before and after the atmospheric correction. Note that coral reef areas are clearly visible after the correction is applied.

where

$$
\begin{array}{ll}
a(\lambda) & \text { total absorption coefficient (per meter); } \\
b_{b}(\lambda) & \text { backscattering coefficient (per meter); } \\
H & \text { depth of water in meters; } \\
\rho(\lambda) & \text { bottom albedo. }
\end{array}
$$

The angular dependency of the remote sensing reflectance (subsurface solar zenith angle, sensor zenith angle) are not explicitly stated in (18) and (19); however, they are included in the coefficients of the equations.

The backscattering coefficient may be expressed as

$$
b_{b}(\lambda)=b_{b p}(\lambda)+b_{b w}(\lambda)
$$

where

$b_{b p} \quad$ backscattering by particles (per meter);

$b_{b w}$ backscattering by water molecules (per meter) taken from Morel [37].

Gordon et al. [18] and Morel [19] proposed different forms of bio-optical algorithms to approximate the backscattering by particles and is incorporated in the (20) as

$$
b_{b}(\lambda)=b_{b p}(660)\left(\frac{660}{\lambda}\right)^{\eta}+b_{b w}(\lambda)
$$

where

$\eta$ coefficient whose values for ocean particles range from 0.0 to 3.0 ;

$\eta \quad 0.5$ is chosen for this coastal study because it is Case-1 water, where concentration of chlorophyll and other biogenic materials is higher compared to nonbiogenic particles.

To estimate $b_{b p}(660)$, we assume there is no contribution from the bottom to the upwelling signal in band $3(664.8 \mathrm{~nm})$, where the absorption is large $\left(>0.4 \mathrm{~m}^{-1}\right)$ and dominated by water molecules. Hence, for relatively clear water deeper than $1.5 / a_{w}(660)$, where bottom effects are small, the backscattering coefficients by particles can be expressed as [38]

$$
b_{b p}(660) \approx \frac{a_{w}(660)}{0.05} R_{r s}(660)
$$

where

$a_{w} \quad$ pure-water absorption coefficient of water taken from Pope and Fry [39]. 

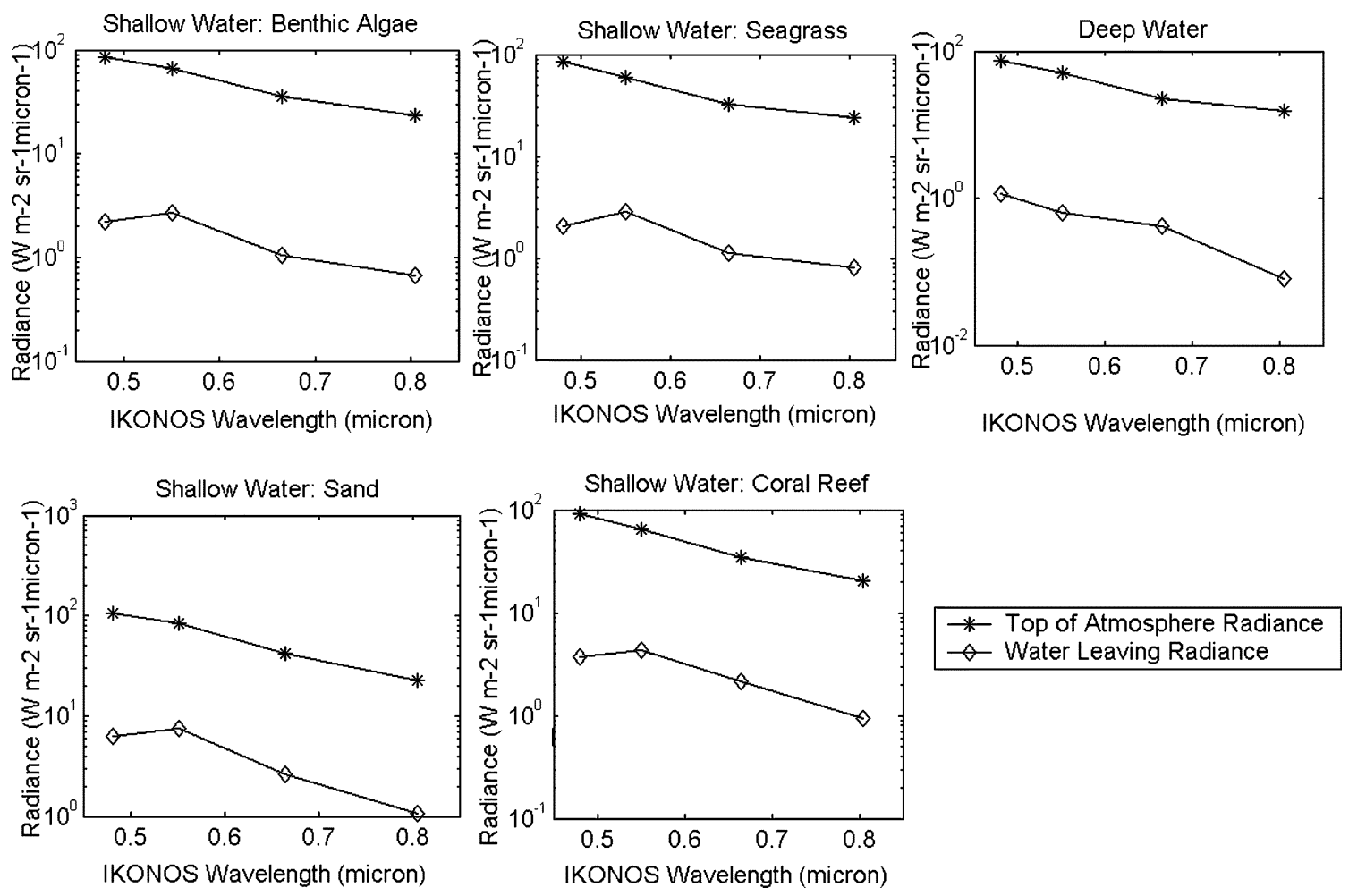

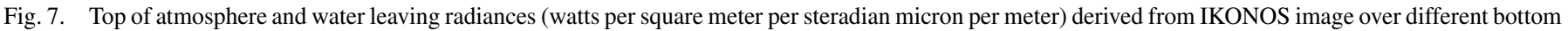
types. Note that more than $80 \%$ of radiance is contribution from the atmosphere.

The total absorption coefficient $a(\lambda)$ can be derived by modification of Austin and Petzold [40] as

$$
a(\lambda)=M(\lambda)\left[a(485)-a_{w}(485)\right]+a_{w}(\lambda)
$$

where

$M \quad$ statistically derived coefficients taken from Austin and Petzold [40];

$a(485) \quad$ total absorption coefficient at $485 \mathrm{~nm}$;

$a_{w}(485) \quad$ pure-water absorption coefficient at $485 \mathrm{~nm}$.

According to Lee et al. [41], the total absorption coefficient at $440 \mathrm{~nm}, a(440)$, over deep water, can be empirically determined by the following equation:

$a(440)=10^{-0.619-1.969\left(\log _{10}\left(\frac{R_{r s}(485)}{R_{r s}(560)}\right)\right)+0.790\left(\log _{10}\left(\frac{R_{r s}(485)}{R_{r s}(560)}\right)\right)^{2}}$

where

$R_{r s}(485)$ remote sensing reflectance at $485 \mathrm{~nm}$;

$R_{r s}(560)$ remote sensing reflectance at $560 \mathrm{~nm}$.

We can thus rewrite the (23) to compute the total absorption coefficient at $485 \mathrm{~nm}$ as

$$
a(485)=\frac{a(440)-a_{w}(440)}{M(440)}+a_{w}(485) .
$$

Note that the models to derive absorption and backscattering coefficients discussed above use wavelengths such as 485, 560, and $660 \mathrm{~nm}$, and in our case, applied to IKONOS blue, green, and red band centers (480.3, 550.7, and $664.8 \mathrm{~nm}$, respectively). Equation (23) is applied over deep-water pixels (white square in Fig. 1) to compute the water absorption coefficients for the blue, green, and red bands of the IKONOS dataset. Deep-water pixels were defined as those having very little upwelling signal in the visible bands of the dataset and are not affected by bottom albedo, i.e., they comprise optically deep areas. A $50 \times 50$ pixel window was identified (white square in Fig. 1) as having very little water leaving radiance values in all visible bands. The total absorption coefficients derived from that region are assumed to be constant over the entire scene. Absorption and backscattering coefficients for each IKONOS band were derived using [(21), (23), and (25)] (Table I). The water depth and optical parameters were used to derive the bottom albedo image (19) from which benthic information could be extracted using standard image processing procedures.

\section{G. Image Classification}

Prior to implementing a spectral pattern recognition algorithm, a classification scheme was developed that included the following categories: 1) dense seagrass; 2) Mixed: seagrass/sand/algae; 3) Mixed: coral/sand; 4) sand; 5) coral; and 6) deep water. These six aquatic feature classes were selected based on the availability of sufficient replication of ground control data to verify feature locations in a later classification analysis. The iterative self-organizing data (ISODATA) algorithm was used on the bottom albedo image composed of three bands to derive 150 statistically different clusters [26]. Using a maximum-likelihood classifier, these clusters were assigned to the benthic categories with the highest probability of being a member. Finally a comprehensive evaluation of the classification accuracy was performed based on 651 reference points, digital still photographs, and digital video images taken by the towfish, as well as photos taken by the divers comprising our field team. 


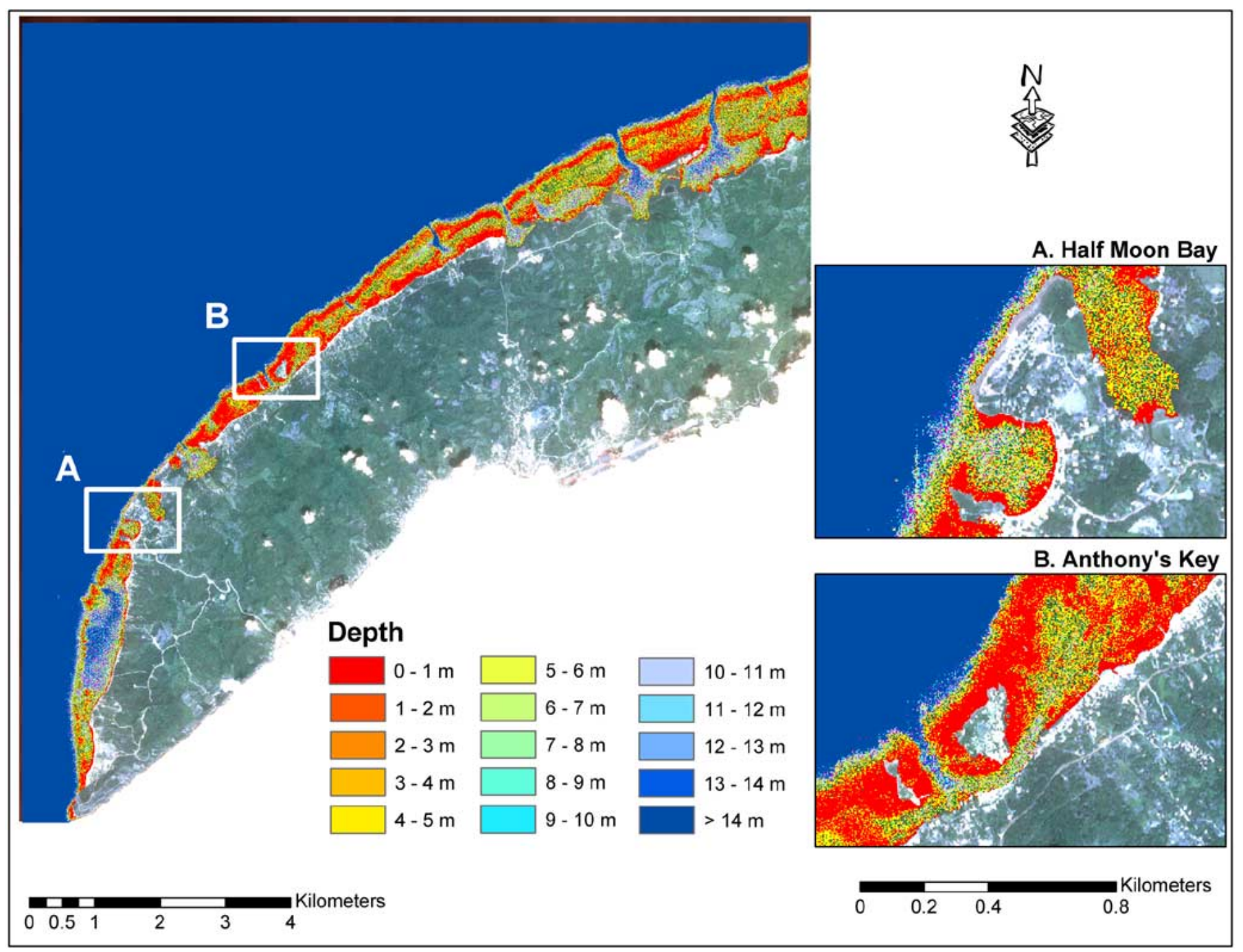

Fig. 8. Bathymetric image-map of Roatan Island based on the polynomial model along with two zoomed insets of (a) Half-Moon Bay and (b) Anthony's Key areas for visualizing the detail depicted by the bathymetric model.

\section{RESULTS}

Visual examination of the images before and after the atmospheric correction procedure (Fig. 6) showed sharp differences between them. For example the coral areas in the zoomed insets (light brown) showed a linear trend $(\mathrm{N}-\mathrm{S})$ after the atmospheric correction. The haziness depicted in the original IKONOS image, attributed to Rayleigh and aerosol scattering, was eliminated resulting in a visually clear image. Radiance values of water over different bottom types were analyzed before and after the atmospheric correction. Because TOA radiance values are dominated by Rayleigh and aerosol path radiance, it becomes difficult to infer the spectral properties of water over different benthic substrates. To fully understand this concept, known pixels depicting water over five locations including benthic alage, seagrass, deep water, sand, and coral reef areas were selected (Fig. 7). After the atmospheric correction was implemented, the corrected profiles showed the spectral variability in greater detail. For example, water leaving radiance in the NIR becomes $\approx 0$ in all the cases because of high NIR absorption by water. Similarly, dark targets such as seagrass areas and deep water showed low radiance values in all visible bands. Water leaving radiance in shallow waters always contains a fraction of upwelling radiance of the underlying benthic habitat. When comparing water leaving radiance over shallow areas, submerged sand, or coral reefs to seagrass areas, it can be observed that the seagrass substrate, being darker, has low upwelling radiance. Conversely, submerged sand (being the brightest substrate) had the maximum radiance values. In general, the blue and green bands were found to have the highest water leaving radiance among all IKONOS bands. Specific absorption features of different benthic bottom types are not identifiable because of the water column attenuation and the broadband nature of the IKONOS sensor.

A bathymetric map (Fig. 8) generated using (14), when compared to the original IKONOS image (i.e., Fig. 1), visual observations of similarities in bottom patterns can be made in both the image and the map. Two areas [Half-Moon Bay (A) and Anthony's Key (B)] are depicted in a large format because our research team has collected in situ data there annually since 1999. A visual examination of the image map reveals the details of variations in depth at the two sites. The deep channel near the Anthony's Key shows a depth of $>12 \mathrm{~m}$, which is 


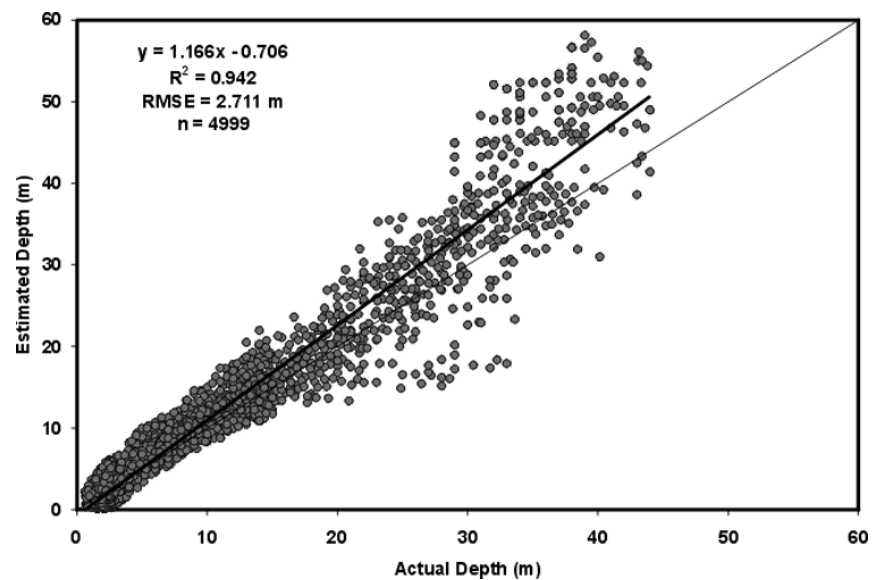

Fig. 9. Plot of actual versus estimated depths using model validation dataset taken from the towfish.

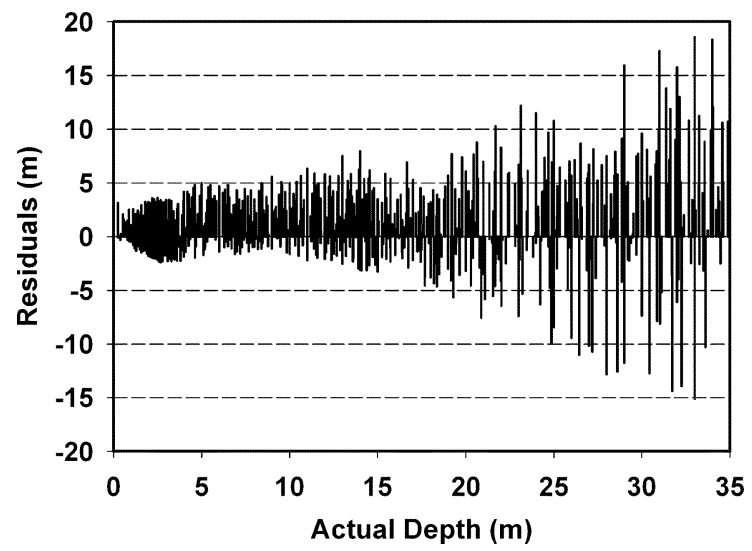

Fig. 10. Histogram plot of depth residuals from the regression model versus actual depth. Note that no particular pattern of over- or underestimation was observed.

reasonable given our knowledge of the site. The depth variation around the zoomed areas of Half-Moon Bay and Anthony's Key was high, which is generally true in the coral reef marine environment because of their uneven morphological structure. Using 4999 in situ depth points, the bathymetric map was validated for its accuracy and the root mean square (rms) error was calculated. When analyzing the accuracies of estimated depths, it was found that the correlation coefficient between actual depth and estimated depth was 0.942 (Fig. 9), with an rms error of $2.711 \mathrm{~m}$. The slope and intercept of the trend line were found to be 1.166 and 0.706 , respectively. From the errors in modeling the dependence of depth with band ratio $L_{w}$ (blue) $/ L_{w}$ (green) (Fig. 5) it was observed that $x \leq 0.25$, the calibration points are roughly evenly distributed about the curve. However, for $x>0.25$, the points are mostly below the calibration curve thus indicating that the model overestimates depths beyond $21 \mathrm{~m}$. Residuals were calculated by subtracting estimated depths from actual depths and revealed no clear pattern of over/underestimation (Fig. 10).

The absorption and backscattering parameters for the three IKONOS bands are specified at the band centers (Table I). As the wavelength increased, there was an increase in the total

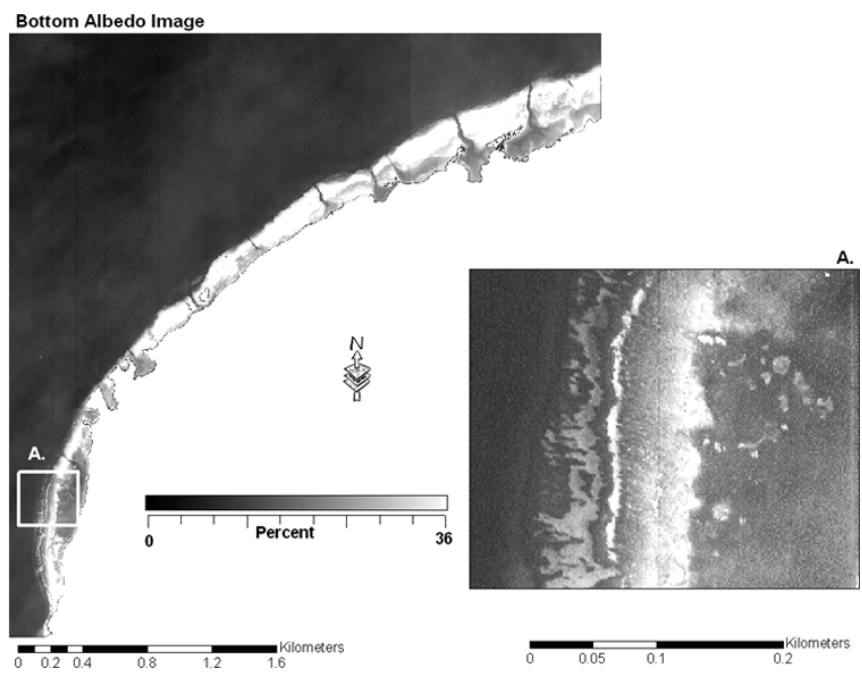

Fig. 11. Image showing bottom albedo (band 2: green band) varying from $0 \%$ to $36 \%$ with (a) a zoomed inset for visualizing the details depicted by the albedo image. The dark region in the zoomed image is seagrass benthos (albedo $\leq 12 \%$ ). The gray region is coral-dominated areas ( $12 \%$ to $24 \%$ ), whereas bright regions are sand-dominated areas $(\geq 24 \%)$.

absorption coefficient, which is due to the fact that the phytoplankton pigments and water itself shows high absorption in the red spectrum. The waters off Roatan Island, where the concentration of phytoplankton (chlorophyll range: $0.031-1.81 \mathrm{mg} / \mathrm{l}$, seston range: $0.319-4.091 \mathrm{mg} / \mathrm{l}$, based on field measurements) is greater than nonbiogenic particles, are considered as Case-1 waters. Absorption by chlorophyll and related pigments therefore plays a major role in determining the total absorption coefficient in such waters; although detritus and dissolved organic matter derived from the phytoplankton also contribute to absorption in Case-1 waters. Because backscattering is wavelength dependent, a higher coefficient was observed in blue band than in the red. Absorption and backscattering coefficients along with water depth were incorporated in (19) to generate a bottom albedo image (Fig. 11). The dark region on the albedo image (green band) is the deep water region with depths deeper than $21 \mathrm{~m}$. The zoomed inset shows the detailed variation in bottom albedo based on the substrate reflectance. Dark regions are comprised of seagrasses with albedo $\leq 12 \%$, while the bright regions represent sand-dominated areas with albedo $\geq 24 \%$. Coral-dominated areas manifested albedos in the range of $12 \%$ to $24 \%$ depending upon the percent of live coral cover occurring in each pixel. The effectiveness of the water column correction is evident from the fact that differences in radiance between deep and shallow sand observed in Fig. 6 are eliminated in the albedo image, and all sand-dominated areas have approximately the same albedo.

An ISODATA classification algorithm was applied to the bottom albedo image resulting 150 clusters and each cluster was assigned to a particular benthic class with the help of in situ data, towfish images, and still photographs derived from the video camera (Fig. 12). A comparative evaluation of the classified image versus 651 independent in situ points (GPS location, towfish image) revealed an overall accuracy of $80.645 \%$ (Table II). An examination of producer's and 


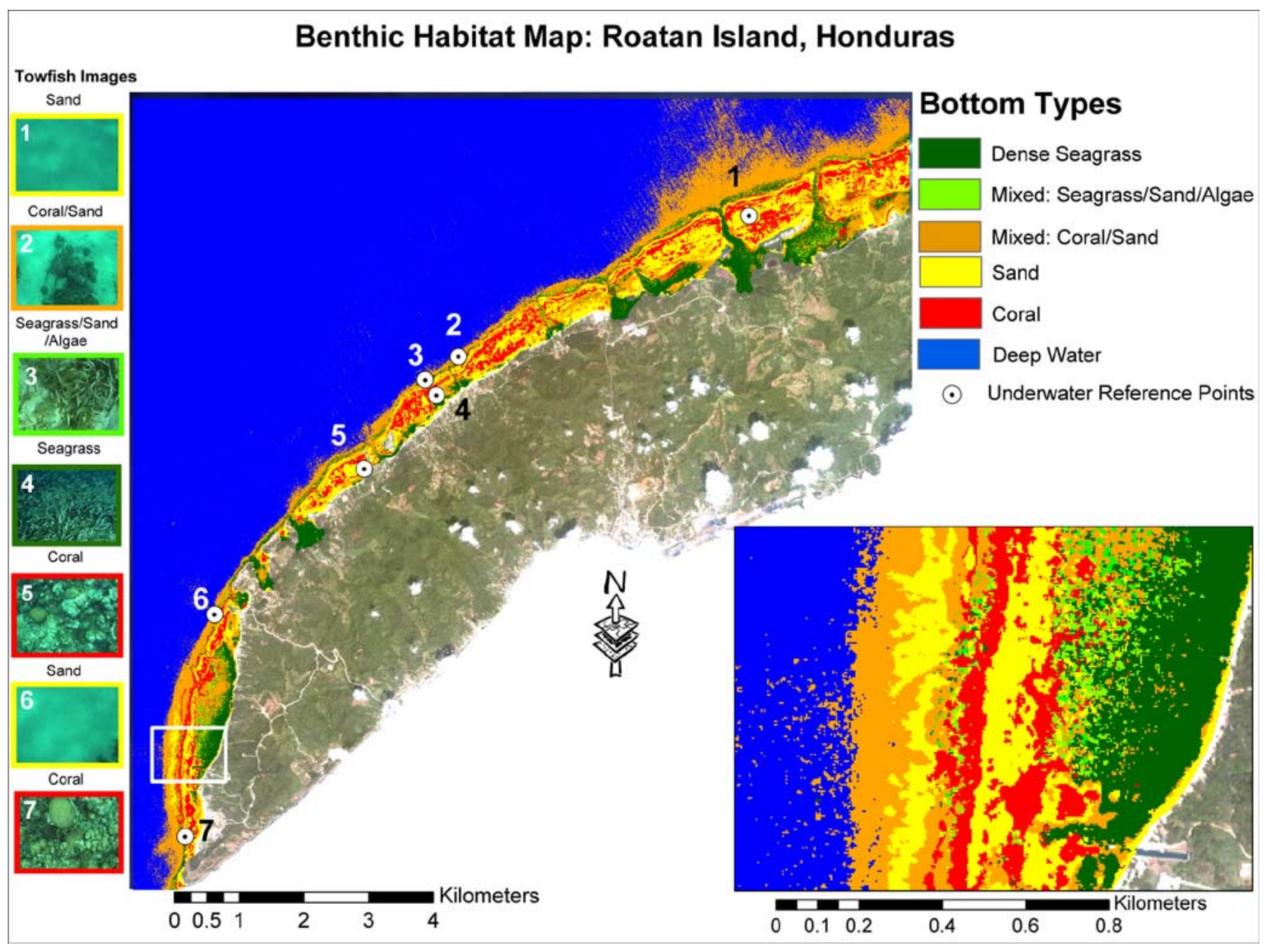

Fig. 12. Color-coded map showing different benthic habitats off the northwest coast of Roatan Island, Honduras. This map resulted from an unsupervised classification of the above shown bottom albedo image. White circle points shown in the map are representative ground points, where photographs of the bottom types were acquired by the towfish. The border color of each photograph matches the color given to a particular class.

user's accuracies also showed better classification results with IKONOS data versus those derived from Landsat TM or SPOT XS data [12]. Sand and deep water areas showed the highest producer's and user's accuracies, when compared to dense seagrass, Mixed: seagrass/sand/algae, and Mixed: coral/sand areas. This indicates that confusion between the latter classes during the ISODATA classification were high, due to their similar spectral characteristics. Sand (very bright), and deep water (very dark) are two most spectrally distinct classes, with the highest spectral separability and lowest classification error. The coral benthic class showed intermediate producer's and user's accuracies of $84 \%$ and $81 \%$, respectively. The overall kappa statistic, a discrete multivariate accuracy assessment technique described by Congalton and Mead [42], was 0.774 (Table II). This statistic estimates the percent of successful classifications compared to a random, chance classification assignment [26]. There are several reasons for the confusion error in the three classes (mentioned above), including limitations of the spectral sensitivity of the broad band IKONOS satellite, and spectral overlaps between optically similar objects (i.e., the calcium carbonate skeleton of a dead coral is optically similar to sparse seagrass with a sand background, while algal overgrowth is often similar to zooxanthalle densities and pigmentation occurring in coral features). Previous studies using coarser resolution satellite data (i.e., Landsat TM) have normally achieved accuracies of only $37 \%$, even when compensating for the confounding effects of variable water depths [12]. The major problem with the classification at our study area was primarily associated with the presence of sand in reef areas, and from rapid changes of coral diversity and reef features over relatively short distances, often in areas of patch reefs.

\section{DISCUSSION}

The IKONOS satellite sensor has three visible bands centered at 480.3, 550.7, and $664.8 \mathrm{~nm}$, which can be used for shallow marine applications. In this research we proposed practical methods to remove atmospheric and water column effects from IKONOS image making it robust for benthic habitat mapping. However, this method is dependent on the extraction of dark water pixels to derive absorption and backscattering coefficients, as well as depth sounding data which may not be available in a particular scene or for a given site. 
TABLE II

RESUlts of ACCURACY ASSESSMENT BASED ON 651 UndERWATER REFERENCE POINTS. THE ClasSIFICATION RESUlTS SHOWED AN OVERALL ACCURACY OF 80.645\%, WHEREAS THE OVERALl KAPPA WAS Found TO Be 0.774

\begin{tabular}{|c|c|c|c|c|c|c|c|c|c|c|}
\hline Benthic Type & $\begin{array}{l}\text { Dense } \\
\text { Seagrass }\end{array}$ & $\begin{array}{c}\text { Mixed: } \\
\text { Seagrass/Sand/ } \\
\text { Algae }\end{array}$ & $\begin{array}{c}\text { Mixed: } \\
\text { Coral/Sand }\end{array}$ & Sand & Coral & $\begin{array}{l}\text { Deep } \\
\text { Water }\end{array}$ & Row Total & $\begin{array}{c}\text { Produces } \\
\text { Accuracy } \\
(\%)\end{array}$ & $\begin{array}{c}\text { Users } \\
\text { Accuracy } \\
(\%)\end{array}$ & $\begin{array}{c}\text { Kappa } \\
\text { Coefficient }\end{array}$ \\
\hline Dense Seagrass & 69 & 18 & 4 & 0 & 7 & 6 & 104 & 75.82 & 66.35 & 0.810 \\
\hline $\begin{array}{c}\text { Mixed: } \\
\text { Seagrass/Sand/ } \\
\text { Algae }\end{array}$ & 11 & 95 & 5 & 0 & 2 & 0 & 113 & 72.52 & 84.07 & 0.808 \\
\hline $\begin{array}{c}\text { Mixed: } \\
\text { Coral/Sand }\end{array}$ & 0 & 9 & 43 & 0 & 8 & 0 & 60 & 57 & 72 & 0.813 \\
\hline Sand & 0 & 0 & 11 & 109 & 5 & 0 & 125 & 95.61 & 87.20 & 0.808 \\
\hline Coral & 4 & 9 & 12 & 5 & 131 & 0 & 161 & 83.97 & 81.37 & 0.803 \\
\hline Deep Water & 7 & 0 & 0 & 0 & 3 & 78 & 88 & 92.86 & 88.64 & 0.811 \\
\hline Column Total & 91 & 131 & 75 & 114 & 156 & 84 & $\begin{array}{c}\text { Total } \\
651\end{array}$ & & & \\
\hline & \multicolumn{2}{|c|}{$\begin{array}{r}\text { Overall Accuracy }= \\
80.645 \%\end{array}$} & \multicolumn{2}{|c|}{$\begin{array}{c}\text { Overall Kappa } \\
\text { Coefficient }=0.774\end{array}$} & & & & & & \\
\hline
\end{tabular}

In our study, sand, seagrass, and coral hard bottom reefs were the most abundant near-shore features. Although these features have different spectral characteristics and can be separable as homogenous pixels, in reality there can be a significant amount of intermixing between these features, even at a spatial resolution of $4 \times 4 \mathrm{~m}$. Specific problems such as complex feature combinations; sand-dominated areas with variable amounts of algal cover; variation in color, texture, size; and error in depth estimation can also have a considerable impact on the classification results. Additional classes could possibly be identified and validated with a more intense classification algorithm and extensive field campaign. Deriving detailed ecological and biological information for each in situ data point would increase the number of elements separable by a classification scheme. However, such approaches require more field sampling to acquire sufficient statistical replication for each class. The primary goal of this research was to assess the utility of the higher spatial resolution of the IKONOS data for mapping benthic communities. When compared to studies that have utilized other commercial sensors such as the Landsat TM or SPOT XS, this research produced improved classification accuracies, and improved discrimination between basic benthic communities.

It is important to note that coral stress and/or bleaching may add to confusion in image classifications. As corals become stressed and loose their pigmentation, the underlying calcium carbonate skeletons become exposed. This highly reflective material can more easily be confused with the high signal return from sand and bare rock features. Soon after the coral die off, the remaining skeletons become covered with algae and pitted through bio-erosion. These ecological changes reduce the overall albedo and may lead to confusion with live coral and/or microalgae features. Close-range hyperspectral studies that can aid in discriminating between the mortality states of live and algae covered coral skeletons (e.g., [43]) can be used to develop baseline spectra that can be used in minimizing spectral confusion in satellite imagery. Further research should focus on using IKONOS higher spatial data to address certain key issues that are of vital interest to the biological community, especially the detection of stress effects and structural changes.

\section{ACKNOWLEDGMENT}

The authors appreciate the assistance of the Galindo family and the staff of Anthony's Key Resort, Roatan Island, Honduras. The authors also thank staff at the Roatan Institute for Marine Science, especially Jennifer Keck, for their assistance and use of facilities during our field work at that location. All image processing was performed using ERDAS Imagine 8.7; Matlab 6.5.

\section{REFERENCES}

[1] M. Khan, Y. Fadlallah, and K. Al-Hinai, "Thematic mapping of subtidal coastal habitats in the Western Arabian Gulf using Landsat TM data: Abu Ali Bay, Saudi Arabia," Int. J. Remote Sens., vol. 13, no. 4, pp. 605-614, 1992.

[2] J. Michalek, T. Wagner, J. Luczkovich, and R. Stoffle, "Multispectral change vector analysis for monitoring coastal marine environments," Photogramm. Eng. Remote Sens., vol. 59, no. 3, pp. 381-384, 1993.

[3] W. Ahmad and D. Neil, "An evaluation of Landsat Thematic Mapper digital data for discriminating coral reef zonation: Heron Reef (GBR)," Int. J. Remote Sens., vol. 15, no. 13, pp. 2583-2597, 1994.

[4] T. Matsunaga and H. Kayanne, "Observation of coral reefs on Ishigaki Island, Japan using Landsat TM images and aerial photographs," in Proc. 4th Int. Conf. Remote Sensing for Marine and Coastal Environments, vol. 1, Orlando, FL, 1997, pp. 657-666.

[5] E. Dobson and P. Dustan. The use of satellite imagery for detection of shifts in coral reef communities. presented at Amer. Soc. Photogramm. Remote Sensing 
[6] D. Peddle, E. LeDrew, and H. Holden, "Spectral mixture analysis of coral reef abundance from satellite imagery and in-situ ocean spectra, Savusavu Bay, Fiji," in Proc. 3rd Thematic Conf. Remote Sensing for Marine and Coastal Environments, vol. II, Seattle, WA, 1995, pp. 563-575.

[7] E. LeDrew, H. Holden, M. Wulder, C. Derksen, and C. Newman, "A spatial statistical operator applied to multidate satellite imagery for identification of coral reef stress," Remote Sens. Environ., vol. 91, pp. 271-279, 2004

[8] P. Mumby, C. Clark, E. Green, and A. Edwards, "Benefits of water column correction and contextual editing for mapping coral reefs," Int. J. Remote Sens., vol. 19, pp. 203-210, 1998.

[9] S. Maritorena and N. Guillocheau, "Optical properties of the water and spectral light absorption by living and nonliving particles and by yellow substances in coral reef waters of French Polynesia," Marine Ecol. Progr. Series, vol. 131, pp. 245-255, 1996.

[10] E. LeDrew, H. Holden, D. Peddle, J. Morrow, R. Murphy, and W. Bour, "Toward a procedure for mapping coral stress from SPOT imagery with in situ optical correction," in Proc. 3rd Thematic Conf. Remote Sensing of the Marine Coastal Environment, vol. 1, Seattle, WA, 1995, pp. 211-219.

[11] P. J. Mumby, J. R. M. Chisholm, J. D. Hedley, C. D. Clark, and J. Jaubert, "A bird's-eye view of the health of coral reefs," Nature, vol. 413, no. 6852, p. 36, 2001.

[12] P. Mumby, A. Edwards, C. Clark, and E. Green, "Managing tropical coastal habitats," Backscatter, pp. 22-26, May 1998.

[13] F. C. Polycn and I. J. Sattinger, "Water depth determination using remote sensing techniques," in Proc. 6th Int. Symp. Remote Sensing of Environment, Ann Arbor, MI, 1969, pp. 1017-1028.

[14] D. Lyzenga, "Passive remote sensing techniques for mapping water depth and bottom features," Appl. Opt., vol. 17, pp. 379-383, 1978.

[15] Z. Lee, K. L. Carder, S. K. Hawes, R. G. Steward, T. G. Peacock, and C. O. Davis, "A model for interpretation of hyperspectral remote-sensing reflectance," Appl. Opt., vol. 33, pp. 5721-5732, 1994.

[16] Z. Lee, K. L. Carder, R. G. Steward, T. G. Peacock, C. O. Davis, and J. L. Mueller, "Remote-sensing reflectance and inherent optical properties of oceanic waters derived from above-water measurements," in Proc. SPIE, vol. 2963, 1996, pp. 160-166.

[17] Z. Lee, K. L. Carder, C. D. Mobley, R. G. Steward, and J. S. Patch, "Hyperspectral remote sensing for shallow waters: 2. Deriving bottom depths and water properties by optimization," Appl. Opt., vol. 38, pp. $3831-3843,1999$.

[18] H. R. Gordon, O. B. Brown, R. H. Evans, J. W. Brown, R. C. Smith, K. S. Baker, and D. K. Clark, "A semianalytic radiance model of ocean color," J. Geophys. Res., vol. 93, pp. 10909-10924, 1998.

[19] A. Morel, "Optical modeling of the upper ocean in relation to its biogenous matter content (case 1 waters)," J. Geophys. Res., vol. 93, pp. 10749-10768, 1988 .

[20] W. V. Davidson, Historical Geography of the Bay Islands, Honduras. Birmingham, AL: Southern Univ. Press, 1974, p. 199.

[21] J. Keck, Instructor's Guide. Roatan, Bay Islands, Honduras: Roatan Inst. Marine Sci., 2000, p. 70.

[22] J. R. Jensen, S. Narumalani, O. Weatherbee, and H. E. Mackey, "Remote sensing offers an alternative for mapping wetlands," Geo Inf. Syst., vol. 1, pp. 46-53, 1991.

[23] J. T. O. Kirk, Light and Photosynthesis in Aquatic Ecosystems. Cambridge, U.K.: Cambridge Univ. Press, 1994, p. 509.

[24] H. R. Gordon, D. K. Clark, J. W. Brown, O. B. Brown, R. Evans, and W. W. Broenkow, "Phytoplankton pigment concentrations in the Middle Atlantic Bight: comparison of ship determinations and CZCS estimates," Appl. Opt., vol. 22, no. 1, pp. 20-36, 1983.

[25] H. R. Gordon and K. J. Voss, "MODIS normalized water-leaving radiance algorithm theoretical basis document," Univ. Miami, Coral Gables, FL, Tech. Rep. MOD 18, NAS5-31 363, vol. 93, Apr. 1999.

[26] J. R. Jensen, Introductory Digital Image Processing a Remote Sensing Perspective. Upper Saddle River, NJ: Prentice-Hall, 1996, p. 318.

[27] H. R. Gordon and D. K. Clark, "Clear water radiances for atmospheric correction of coastal zone color scanner imagery," Appl. Opt., vol. 20, pp. 4175-4180, 1981

[28] H. Nickel and D. Labs, "The solar radiation between 3300 and 12500 A," Solar Phys., vol. 90, pp. 205-258, 1984.

[29] J. E. Hansen and L. D. Travis, "Light scattering in planetary atmospheres," Space Sci. Rev., vol. 16, pp. 527-610, 1974.

[30] R. Doerffer, "Imaging spectroscopy for detection of chlorophyll and suspended matter," in Imaging Spectroscopy: Fundamentals and Prospective Applications, F. Toselli and J. Bodechtel, Eds. London, U.K.: Kluwer, 1992, pp. 215-257.
[31] H. R. Gordon and M. H. Wang, "Retrieval of water-leaving radiance and aerosol optical-thickness over the oceans with Seawifs-A preliminary algorithm," Appl. Opt., vol. 33, pp. 443-452, 1994.

[32] B. Leckner, "The spectral distribution of solar radiation at the earth's surface; Elements of a model," Solar Energy, vol. 20, pp. 143-150, 1978.

[33] F. C. Polcyn, W. L. Brown, and I. J. Sattinger, "The measurement of water depth by remote sensing techniques," Willow Run Lab., Univ. Michigan, Ann Arbor, Rep. 8973-26-F, 1970.

[34] W. D. Philpot, "Bathymetric mapping with passive multispectral imagery," Appl. Opt., vol. 28, no. 8, pp. 1569-1578, 1989.

[35] H. R. Gordon and O. B. Brown, "Influence of bottom albedo on the diffuse reflectance of a flat homogeneous ocean," Appl. Opt., vol. 13, pp. 2153-2159, 1974.

[36] C. D. Mobley, Light and Water: Radiative Transfer in Natural Waters. San Diego, CA: Academic, 1994, p. 592.

[37] A. Morel, "Optical properties of pure water and pure seawater," in $O p$ tical Aspects of Oceanography, N. G. Jerlov and E. Steeman Nielsen, Eds. New York: Academic, 1974, pp. 1-24.

[38] A. Y. Morel and B. Gentili, "Diffuse reflectance of oceanic waters II. Bi-directional aspects," Appl. Opt., vol. 32, no. 33, pp. 6864-6879, 1993.

[39] R. M. Pope and E. S. Fry, "Absorption spectrum (380-700 Nm) of pure water. 2. Integrating cavity measurements," Appl. Opt., vol. 36, pp. 8710-8723, 1997.

[40] R. W. Austin and T. J. Petzold, "The determination of the diffuse attenuation coefficient of sea water using the coastal zone color scanner," in Oceanography From Space, J. F. R. Gower, Ed. New York: Plenum, 1986, pp. 239-256.

[41] Z. P. Lee, K. L. Carder, C. D. Mobley, R. G. Steward, and J. S. Patch, "Hyperspectral remote sensing for shallow waters. 1. A semi-analytica model," Appl. Opt., vol. 37, pp. 6228-6329, 1998.

[42] R. G. Congalton and R. A. Mead, "A quantitative method to test for consistency and correctness in photointerpretation," Photogramm. Eng. Remote Sens., vol. 49, no. 1, pp. 69-74, 1983

[43] C. D. Clark, P. J. Mumby, J. R. M. Chisholm, J. Jaubert, and S. Andrefouet, "Spectral discrimination of coral mortality states following a severe bleaching event," Int. J. Remote Sens., vol. 21, no. 11, pp. 2321-2327, 2000

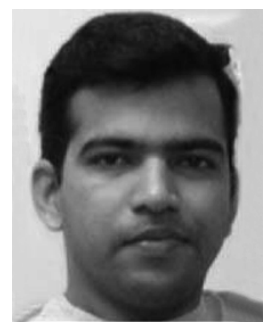

Deepak R. Mishra received the M.Tech. degree in civil engineering from the Indian Institute of Technology, Kanpur. He is currently pursuing the Ph.D. degree at the University of Nebraska, Lincoln. His $\mathrm{Ph} . \mathrm{D}$ dissertation is on remote sensing of coral reefs at Roatan Island, Honduras.

His research focuses on using space- and airborne remote sensing for coastal applications. He has also performed research on the ecological applications of remote sensing techniques.

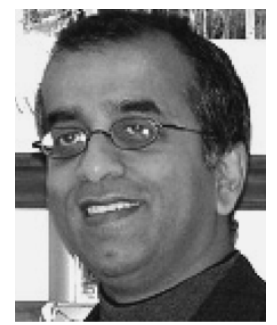

Sunil Narumalani received the Ph.D. degree in geography from the University of South Carolina, Columbia.

$\mathrm{He}$ is currently an Associate Professor in the School of Natural Resources, University of $\mathrm{Ne}-$ braska, Lincoln, and a full-time Faculty Associate at the Center for Advanced Land Management Information Technologies, University of Nebraska. He teaches courses in remote sensing (digital image analysis) and advanced geographic information systems. His research focuses on the use of remote sensing for the extraction of biophysical information from space- and airborne systems, integration of geospatial datasets for ecological and natural resources mapping and monitoring, and the development of new image processing analyses techniques for information extraction. 


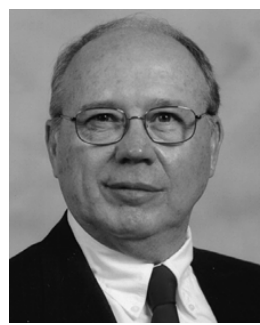

Donald Rundquist received the Ph.D. degree in geography from the University of Nebraska, Lincoln, in 1977.

He is currently a Professor with the School of Natural Resources, Institute of Agriculture and Natural Resources, University of Nebraska. He also serves as Director of the Center for Advanced Land Management Information Technologies, University of Nebraska. His research is focused on field techniques in remote sensing, especially as they relate to the status and condition of cropland vegetation and the quality of surface waters. He also has research interests in the applications of high spatial and spectral resolution airborne remote sensing to those same issues.

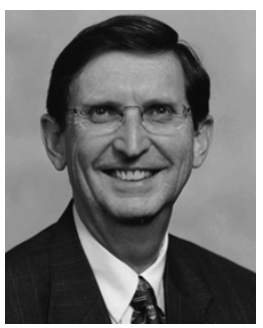

Merlin Lawson received the Ph.D. degree in geography from Clark University, Worcester, MA.

He is currently a Professor of geosciences and Dean Emeritus at the University of Nebraska, Lincoln. He also holds a courtesy research appointment at the Center for Advanced Land Management Information Technologies, University of Nebraska. He teaches courses in meteorology and climate change. His research currently focuses on the impact of global warming on the health status of coral reefs as monitored by in situ, airborne, and satellite image analysis. 